\title{
Prevention behavior of community for spreading COVID-19 in West Kalimantan Province, Indonesia
}

\author{
Linda Suwarni $^{1}$, Selviana Selviana ${ }^{2}$, Mawardi Mawardi ${ }^{3}$, Marlenywati Marlenywati ${ }^{4}$, Nilasari \\ Nilasari $^{5}$, Suyitno Suyitno ${ }^{6}$, Maretalinia Maretalinia ${ }^{7}$ \\ 1,2,3,4 Fakultas Ilmu Kesehatan, Universitas Muhammadiyah Pontianak, Pontianak, Indonesia \\ ${ }^{5}$ Faculty of Medicine, Public Health and Nursing, Gadjah Mada University, Yogyakarta, Indonesia \\ ${ }^{6}$ ASEAN Institute for Health Development, Mahidol University, Nakhon Pathom, Thailand \\ ${ }^{7}$ Institute for Population and Social Research, Mahidol University, Nakhon Pathom, Thailand
}

\begin{tabular}{|c|c|}
\hline Article Info & ABSTRACT \\
\hline Article history: & The COVID-19 pandemic caused huge impacts on human being worldwide. \\
\hline & The accumulated infected cases are $156,778,078$ with $3,272,054$ death cases \\
\hline Received Jan 15, 2021 & on May 7 , 2021. Importantly, not many people practice the prevention \\
\hline Revised Aug 7, 2021 & behavior of COVID-19 pandemic. This study measured the prevention \\
\hline Accepted Aug 23, 2021 & $\begin{array}{l}\text { behavior of COVID-19 in West Kalimantan Province, Indonesia by socio- } \\
\text { demographic factors and protection motivations from the community. This }\end{array}$ \\
\hline Keywords: & $\begin{array}{l}\text { study used a cross-sectional design which was carried out for two weeks } \\
\text { from the end of July to early August. The study involved } 385 \text { respondents }\end{array}$ \\
\hline COVID-19 & from 972,635 people in Municipality Pontianak, Municipality Singkawang, \\
\hline Prevention behavior & $\begin{array}{l}\text { and Ketapang Regency, Indonesia. The result showed the majority of the } \\
\text { respondent were female }(74.3 \%) \text {, in adult age group }(61.3 \%) \text {, graduated from }\end{array}$ \\
\hline Protection motivation & university $(51.2 \%)$, and have a job (64.9\%). Multiple logistic regression \\
\hline West Kalimantan province & $\begin{array}{l}\text { s.37), low perception of self-efficacy (Adj. OR=3.44, 95\% C.I=1.98-5.95), } \\
\text { and low the evaluated cost response (Adj. OR=1.94, 95\% C.I=1.20-3.14) } \\
\text { were statistically significant having correlation with poor prevention } \\
\text { behavior of spreading COVID-19. The results can be utilized for the } \\
\text { promotion of protocol of prevention COVID-19, for instance, provide } \\
\text { personal protective equipment (PPE) for people with high-risk occupation } \\
\text { including health personal, promote the importance of practice prevention } \\
\text { behavior, and control the price of basic PPE including mask and ensure all } \\
\text { people have an access to have the mask. }\end{array}$ \\
\hline
\end{tabular}

This is an open access article under the CC BY-SA license.

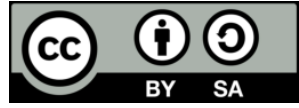

\section{Corresponding Author:}

Selviana Selviana

Lecturer in Faculty of Health Science

Universitas Muhammadiyah Pontianak

A. Yani Street No. 111, Pontianak, West Kalimantan, Indonesia

Email: selviana@unmuhpnk.ac.id

\section{INTRODUCTION}

Declaration of the COVID-19 pandemic by World Health Organization on March 11, 2020 still a serious problem until in the world [1]. Up to November $19^{\text {th }}, 2020$ the global confirmed cases of COVID-19 is 55,326,907 and the deaths are 1,333,742 (mortality rate is 2,4\%) [2]. The prevention way introduced by Ministry of Health Republic Indonesia is including hand washing; do not touch eyes, nose, and mouth; ethics once cough; use the mask; and physical distancing within one meter [3], [4]. Study conducted in United Kingdom and United States found that $86.0 \%$ and $92.6 \%$, respectively know the prevention way to avoid the 
COVID-19 [5]. The spreading of COVID-19 in the community is based on the existing knowledge of the virus and its effect to the quality of life and economy [6]. Ethiopian people showed how knowledge of COVID-19 is significantly influenced by age, educational status, and marital status [7]. The study in China found that age, gender, and religion affected to have the good knowledge for preventing the COVID-19 [8]. The prevention behavior related to knowledge is also showed from the study in United States, Ethiopia, China, and Vietnam [9]-[13]. The prevention practices had the barriers such as the insufficient knowledge and negative attitude based on the study in Vietnam [14].

In order to understand the knowledge, access to official COVID-19 information and education sources was important to increase the implementation of prevention behavior of COVID-19 [8], [15], [16]. Some prevention practices like using the face mask did not show effectively prevent the spreading of COVID-19 [17]. The role of the National Government to encourage people to practice the prevention way is very important [18]. The low implementation of prevention behavior among Nigerians mostly was influenced by low economic status [19]. Other factors such as age, gender, education level, and occupation revealed not significant related to prevention practice of COVID-19. The data on November $19^{\text {th }}, 2020$ from the Department of Health, West Kalimantan Province, Indonesia reported 2,187 confirmed cases which referred it to be red zone. The prevention was already introduced by the provincial government to prevent the spreading of COVID-19 at any level. Although previous research shows that many do not believe in government policies, most Indonesians have taken preventive behavior for COVID-19 [19]. The COVID-19 pandemic is spreading unpredictably, due to many influencing factors. It continues to cause morbidity, mortality, normal life disturbance, and also a burden on health systems. Assessing the prevention behavior related to COVID-19 among the community in West Kalimantan Province, Indonesia would benefit governments or involved organizations in performing any intervention according to the obtained results. Moreover, recommendations from the community would be important information to strengthen the COVID19 response. This study aimed to examine the factors related to the implementation of prevention behavior of COVID-19 in West Kalimantan Province, Indonesia.

\section{RESEARCH METHOD}

\subsection{Study design}

A community based cross-sectional study was carried out in West Kalimantan Province. The data collection was conducted from July to August 2020 after getting approval from the office of the committee for research ethic (KEPK), Faculty of Public Health, Universitas Muhammadiyah Semarang Institutional review board (Certificate of approval No. 373/KEPK-FKM/UNIMUS/2020).

\subsection{Target population, sample size and sampling technique}

The target population consisted of the entire community aged 15-64 years living in Municipality Pontianak, Municipality Singkawang, and Ketapang District in West Kalimantan Province. The number of populations is of 972,635 people. From fourteen districts, only chosen three regions were classified in the local transmission category in this study. About 385 selected respondents volunteered to fill out the google form that we had distributed. This study has used a combination of purposive and snowball techniques to select the respondents to share the link to social media (WhatsApp, Facebook, Instagram, and Telegram) in those three areas.

\subsection{Research instrument}

Data were collected by means of an online questionnaire (Google Form). Prevention Behavior of COVID-19 of people used four categories; I use a mask, I maintain a distance (social distance) of at least one meter, I wash my hands with soap and running water, I use a hand sanitizer when soap and water are not available. It had answer options: Always '2', Sometimes '1', and Never '0'. The questionnaire consists of two parts; socio-demographic characteristics and the construct of Protection Motivation Theory (PMT). Sociodemographic factors were age, gender, education levels, occupation, field of work, degenerative disease history, and COVID-19 cases all around. The PMT construct was measured through 23 questions. Consisting of nine main constructs; Perceptions of vulnerability, Perception of severity, Perceptions of self-efficacy, Efficacy response, the evaluated cost response, protection intention, protection motivation, information circulating, information circulating, resource of information. These items were measured using a 5 scale from Strongly Agree '1', Agree '2', Uncertain '3', Disagree '4', and Strongly Disagree '5'. Then after being analyzed, the category changed to Low $(3,4,5)$ and High $(1,2)$.

Int. J. Public Health Sci., Vol. 10, No. 4, December 2021 : 771 - 777 


\subsection{Data analysis}

Outcome measurement was prevention behavior of COVID-19 (Yes, No) within two weeks in the last July till to the first week in August. Descriptive statistics were used to determine the frequency and percentage. Chi-square test and multiple logistic regressions were used to examine associations between independent variables and prevention behavior of COVID-19 in West Kalimantan Province, Indonesia.

\section{RESULTS AND DISCUSSION}

3.1. Result

The frequency distribution of the respondent's socio-demographic characteristics is presented in Table 1. There were 385 respondents involved in this study. Majority respondents were female (74.3\%). The 236 respondents were included in the criteria for adults $(61.3 \%)$, and with the level of education in higher education as many as 197 respondents (51.2\%). Occupation status, as many as 250 respondents have a job (64.9\%). Meanwhile, to get deeper into the field of workers, 246 respondents worked in the non-health sector $(63.9 \%)$ and 139 respondents worked in the health sector $(36.1 \%)$. Based on the history of degenerative disease information, only 22 respondents had it (5.7\%). Furthermore, for information on COVID-19 cases around the residence, it is known that 334 respondents answered no or there may be cases of COVID-19 $(86.8 \%)$.

Table 1. Socio-demographic characteristic of prevention behavior in West Kalimantan Province

\begin{tabular}{lcc}
\multicolumn{1}{c}{ Variables } & Frequency (n) & Percent (\%) \\
\hline Age & 149 & 38.7 \\
Youth & 236 & 61.3 \\
Adult & & \\
Gender & 99 & 25.7 \\
Male & 286 & 74.3 \\
Female & & \\
Education levels & 4 & 1 \\
$\quad$ Elementary school-middle school & 184 & 47.8 \\
$\quad$ Senior high school & 197 & 51.2 \\
$\quad$ University & & \\
Occupation & 135 & 35.1 \\
Working/not working yet & 250 & 64.9 \\
$\quad$ Have a job & & \\
Field of work & 246 & 63.9 \\
$\quad$ Non-health sector & 139 & 36.1 \\
$\quad$ Health worker & & \\
Degenerative disease history & 363 & 94.3 \\
$\quad$ No/Perhaps 'Yes' & 22 & 5.7 \\
Yes & & \\
COVID-19 cases all around & 334 & 86.8 \\
$\quad$ No/Perhaps 'Yes' & 51 & 13.2 \\
$\quad$ Yes & & \\
\hline
\end{tabular}

The characteristics of the research variables are presented in Table 2. Based on the COVID-19 prevention behavior, it is known that 238 respondents had poor behavior in preventing COVID-19 (61.8\%), and 147 respondents had well $(38.2 \%)$. Meanwhile, 232 respondents had a high perception of vulnerability (60.3\%), 197 respondents had a perception of low severity (51.2\%) and 218 respondents had a high perception of self-efficacy $(56.6 \%)$. Regarding the efficacy response, 219 respondents had a high efficacy response $(56.9 \%)$ and 196 respondents had a low response to the evaluated cost response $(50.9 \%)$. Based on the intention to protect against COVID-19, as many as 335 respondents had high protection intentions (87.0\%), followed by 342 respondents who had high protection motivation (88.8\%), and 255 respondents believed the circulating information related to COVID-19 (66.2\%) with information sources based on social media according to 226 respondents $(58.7 \%)$.

Table 3 (see in Appendix) shows the results of the Chi-square test on each of the variables from the socio-demographic factors and protection motivation variables. The results show that occupation, perception of severity; perceptions of self-efficacy, efficacy response, the evaluated cost response, protection intention, protection motivation, information circulating, and resource of information have significant relationships with COVID-19 prevention behavior.

The results of the analysis using multiple logistic regression test in Table 4 show that the occupation variable (Adj. OR=1.87, 95\% C.I=1.04- 3.37), perception of self-efficacy (Adj. OR=3.44, 95\% C.I=1.985.95), and the evaluated cost response (Adj. OR=1.94, 95\% C.I=1.20-3.14) are the most dominant variables influencing COVID-19 prevention behavior in West Kalimantan Province. 
Table 2. Protection motivation characteristic of prevention behavior in West Kalimantan Province

\begin{tabular}{|c|c|c|}
\hline Variables & Frequency (n) & Percent (\%) \\
\hline \multicolumn{3}{|c|}{ Prevention behavior of COVID-19 } \\
\hline Poor & 238 & 61.8 \\
\hline Good & 147 & 38.2 \\
\hline \multicolumn{3}{|c|}{ Perceptions of vulnerability } \\
\hline Low & 232 & 60.3 \\
\hline High & 153 & 39.7 \\
\hline \multicolumn{3}{|l|}{ Perception of severity } \\
\hline Low & 197 & 51.2 \\
\hline High & 188 & 48.8 \\
\hline \multicolumn{3}{|c|}{ Perceptions of self-efficacy } \\
\hline Low & 167 & 43.4 \\
\hline High & 218 & 56.6 \\
\hline \multicolumn{3}{|l|}{ Efficacy response } \\
\hline Low & 166 & 43.1 \\
\hline High & 219 & 56.9 \\
\hline \multicolumn{3}{|c|}{ The evaluated cost response } \\
\hline Low & 196 & 50.9 \\
\hline High & 189 & 49.1 \\
\hline \multicolumn{3}{|l|}{ Protection intention } \\
\hline Low & 50 & 13.0 \\
\hline High & 335 & 87.0 \\
\hline \multicolumn{3}{|l|}{ Protection motivation } \\
\hline Low & 43 & 11.2 \\
\hline High & 342 & 88.8 \\
\hline \multicolumn{3}{|l|}{ Information circulating } \\
\hline Believe & 255 & 66.2 \\
\hline Unbelieve & 130 & 33.8 \\
\hline \multicolumn{3}{|l|}{ Resource of information } \\
\hline Social media & 226 & 58.7 \\
\hline Health worker & 159 & 41.3 \\
\hline
\end{tabular}

Table 4. Multiple logistic-regression for independent variable and prevention behavior COVID-19

\begin{tabular}{lcccc}
\hline \multicolumn{1}{c}{ Variable } & B & Adj. OR & $95 \%$ CI & p-value \\
\hline Age & -0.152 & 0.859 & $0.485-1.524$ & 0.604 \\
Sex & 0.154 & 1.167 & $0.667-2.041$ & 0.588 \\
Occupation & 0.628 & 1.873 & $1.041-3.370$ & $0.036^{*}$ \\
Degenerative disease history & 0.355 & 1.426 & $0.733-2.774$ & 0.296 \\
Perception of severity & 0.233 & 1.262 & $0.784-2.031$ & 0.338 \\
Perceptions of self-efficacy & 1.234 & 3.436 & $1.983-5.953$ & $<0.001^{*}$ \\
Efficacy response & 0.498 & 1.646 & $0.973-2.783$ & 0.063 \\
The evaluated cost response & 0.665 & 1.944 & $1.204-3.139$ & $0.007^{*}$ \\
Protection intention & 0.914 & 2.494 & $0.568-10.958$ & 0.226 \\
Protection motivation & -1.230 & 0.292 & $0.065-1.325$ & 0.111 \\
Information circulating & 0.281 & 1.324 & $0.818-2.143$ & 0.253 \\
Resource of information & 0.317 & 1.373 & $0.861-2.190$ & 0.183 \\
\hline
\end{tabular}

Note: * p-value <0.05

\subsection{Discussion}

The results of this study indicated that age, gender, and the presence of COVID-19 cases around the respondent's residence were not related (p-value >0.05) with COVID-19 prevention behavior in West Kalimantan. Age was related to the knowledge that a person has in acting, behaving and determining attitudes in a mature manner. The maturity age of a person is in the age range of 36-45 years, because at that age a person will have good grasping power, good thinking power so that he can absorb the information obtained ripe and his knowledge will also be better. Previous research shows there is no relationship between age and COVID-19 prevention behavior in the community [20]. In addition, other studies also showed that there is no relationship between sex and COVID-19 prevention behavior [21]. Its influences in considering ways to manage stress in emergency situations and choosing coping strategies, for example in COVID-19 conditions [22], [23]. The existence of COVID-19 cases around the residence in this study had no relationship with COVID-19 prevention behavior. In previous study, there was a trend in society that felt vulnerable to COVID-19 tending to take precautions by complying with health protocols [24]. The people most vulnerable to COVID-19 are people who have close contact with COVID-19 patients, including caring for COVID-19 patients [25].

Additionally, in term s of perceptions of severity, response efficacy, protection intention, motivation for protection, information circulating, and resource of information variables were unrelated to COVID-19 
prevention behavior in the community. On the other hand, there are three variables that were significantly related like occupation, perceptions of self-efficacy, and the evaluated cost response.

Based on the results described before, until now (05-12-2020) COVID-19 still exists and it needs a clear understanding regarding the prevention of COVID-19 in the community. Employment status influences COVID-19 prevention behavior in West Kalimantan. In this study, job status is categorized into two, namely respondents who have not or do not work including housewives, students, respondents who work as civil servants, private and self-employed. People who work can develop ideas, but on the other hand work can interfere with other personal roles such as anxiety. The status of unemployed mothers has a low level of anxiety [26]. This study in line with previous research which states that there was a relationship between occupation status having correlation with behavior towards COVID-19 [24].

Therefore, the COVID-19 outbreak not only affect to the physical health, but also effect on various aspects, such as: social, mental, physical, psychological and economic. It takes proper communication through experts who believe it is primarily related to the prevention of COVID-19 in the community [27]. The efficacy response assessed in this study was related to $3 M$ (using a mask, maintaining a minimum distance of a meter, and washing hands with soap as often as possible) and using a hand sanitizer when soap and water were not available. Showing self-confidence in others can increase one's contribution in the formation of behavior [28]-[30]. The results of this study indicate that someone who has low self-efficacy perception of implementing the COVID-19 health protocol has a 3.436 times chance of not implementing this preventive behavior. Self-efficacy can be exemplified like in a nurse can produce a results or certain changes. Self-efficacy has been shown to play an important role in various endeavors, if nurses with low self-efficacy will experience difficulties, stress and anxiety can occur [31].

The evaluated cost response variables in this study were related to the convenience of using masks, difficulty in finding a place to wash hands in public places, the price of expensive personal protective equipment (masks, hand sanitizers, and face shields) and the discomfort of keeping a distance from other people. Previous research had suggested the importance of one's intention to behave for the prevention of a disease, that arises from the individual's awareness [32]. The response cost which is evaluated is in line with one's intention, intention is included in the self-concept of a person, and this is dynamic, meaning that it does not escape change. Some aspects will last a certain period of time and some are easy to change according to the situation and conditions experienced [26]. At the beginning of the COVID-19 outbreak, people would have difficulty adapting according to health protocols, especially in finding tools for their own protection. The results of this study showed that someone with a low evaluation cost response in implementing the COVID-19 health protocol have 1.944 time the chance of not implementing COVID-19 prevention behavior. In line with other research that cost response is related to disease prevention behavior in someone [30].

This research has strengh and limitation. Investigation of the prevention behavior of COVID-19 might be the first study in West Kalimantan Province, Indonesia. The data collection via online approach was conducted in two weeks in Pontianak Municipality, Singkawang Municipality, and Ketapang District. The readiness of organizations, people, hardware facilities, and prevention behavior support might be restricted in some areas. However, the results may benefit authorized units to set preventive strategies to control the spread of COVID-19. The limitation of study is the data collected through online survey that potentially bias from the respondents' side.

\section{CONCLUSION}

In summary, we obtained baseline information of prevention behavior towards COVID-19 in West Kalimantan Province. The finding indicates that people who do not have occupation, low perception of selfefficacy, and low the evaluated cost response have poor prevention behavior COVID-19. Some categories mentioned in this research might benefit the government especially authorized units such as the central government, Ministry of Health and local municipalities. The results can be used as basic information for further intervention for promotion of protocol of prevention COVID-19. The practical recommendation can be: distributed the PPE for the risky occupation, such as health personal and ensure they wear the PPE properly. Additionally, perceptions of self-efficacy need to be increase by promote people to practice health protocol during COVID-19 outbreak by $3 M$ (using a mask, maintaining a minimum distance of a meter, and washing hands with soap as often as possible). In terms of the evaluated cost response, stakeholder may control the price of basic PPE, for instance mask so all people from low to high income will have the power of purchase.

\section{ACKNOWLEDGEMENT}

This research funded by the Ministry of Research and Technology/National Research and Innovation Agency (No. SP DIPA-042.06.1.401516/2020). 


\section{REFERENCES}

[1] D. Cucinotta and M. Vanelli, "WHO declares COVID-19 a pandemic," Acta Bio Medica Atenei Parm., vol. 91, no. 1, pp. 157-160, 2020, doi: 10.23750/abm.v91i1.9397.

[2] Ministry of Health Indonesia, "Peta Sebaran," Ministry of Health Indonesia, 2020. [Online]. Available: https://covid19.go.id/peta-sebaran (accessed Nov. 19, 2020).

[3] A. Milliken et al., "Addressing challenges associated with operationalizing a crisis standards of care protocol for the Covid-19 pandemic," NEJM Catal. Innov. Care Deliv., vol. 1, no. 4, 2020, doi: 10.1056/CAT.20.0384

[4] L. Cirrincione et al., "COVID-19 pandemic: Prevention and protection measures to be adopted at the workplace," Sustainability, vol. 12, no. 9, pp. 1-18, 2020, doi: 10.3390/su12093603.

[5] P. Geldsetzer, "Knowledge and perceptions of COVID-19 among the general public in the United States and the United Kingdom: a cross-sectional online survey," Ann. Intern. Med., vol. 173, no. 2, pp. 157-160, 2020,

[6] M. I. Uddin and M. A. Al-khasawneh, "Optimal policy learning for COVID-19 prevention using reinforcement learning,” J. Inf. Sci., pp. 1-3, 2020, doi: 10.1177/0165551520959798.

[7] D. Asmelash and A. Fasil, "Knowledge, Attitudes and Practices Toward Prevention and Early Detection of COVID-19 and Associated Factors Among Religious Clerics and Traditional Healers in Gondar Town, Northwest Ethiopia: A Community-Based Study," Risk Manag. Healthc. Policy, vol. 13, pp. 2239-2250, 2020, doi: 10.2147/RMHP.S277846.

[8] C. Wang et al., "Disease knowledge and attitudes during the COVID-19 epidemic among international migrants in China: a national cross-sectional study," Int. J. Biol. Sci., vol. 16, no. 15, pp. 2895-2905, 2020, doi: 10.7150/ijbs.47075.

[9] S. C. Bailey et al., "Changes in COVID-19 Knowledge, Beliefs, Behaviors, and Preparedness Among High-Risk Adults from the Onset to the Acceleration Phase of the US Outbreak," J. Gen Intern Med, vol. 35, no. 11, pp. 3285-3292, 2020, doi: 10.1007/s11606-020-05980-2.

[10] S. A. Quandt, N. J. LaMonto, D. C. Mora, J. W. Talton, P. J. Laurienti, and T. A. Arcury, "COVID-19 Pandemic among Latinx Farmworker and Nonfarmworker Families in North Carolina: Knowledge, Risk Perceptions, and Preventive Behaviors," Int. J. Environ. Res. Public Health, vol. 17, no. 16, pp. 1-17, 2020, doi: 10.3390/ijerph17165786.

[11] Z. T. Tesfaye, M. B. Yismaw, Z. Negash, and A. G. Ayele, "COVID-19-Related Knowledge, Attitude and Practice Among Hospital and Community Pharmacists in Addis Ababa, Ethiopia," Integr. Pharm. Res. Pract., vol. 9, pp. 105-112, 2020, doi: 10.2147/IPRP.S261275.

[12] Z. Li et al., "Knowledge, attitudes, and practices related to Coronavirus disease 2019 during the outbreak among workers in China: A large cross-sectional study," PLoS Negl. Trop. Dis., vol. 19, pp. 1-12, 2020, doi: 10.1371/journal.pntd.0008584.

[13] H. Van Nhu et al., "Knowledge, Attitudes, and Practices of the Vietnamese as Key Factors in Controlling COVID - 19," J. Community Health, vol. 45, no. 6, pp. 1263-1269, 2020, doi: 10.1007/s10900-020-00919-4.

[14] G. Huynh et al, "Knowledge, Attitude, and Practices Regarding COVID-19 Among Chronic Illness Patients at Outpatient Departments in Ho Chi Minh City," Risk Manag. Healthc. Policy, vol. 13, pp. 1571-78, 2020, doi: 10.2147/RMHP.S268876.

[15] N. Phuc et al., "Preventive behavior of Vietnamese people in response to the COVID-19 pandemic," PLoS One, vol. 15 , no. 9, pp. 1-11, 2020, doi: 10.1371/journal.pone.0238830.

[16] X. Chen and H. Chen, "Differences in preventive behaviors of COVID-19 between urban and rural residents: lessons learned from a cross-sectional study in China," Int. J. Environ. Res. Public Health, vol. 17, no. 12, pp. 1-4, 2020, doi: 10.3390/ijerph17124437.

[17] R. Chou, T. Dana, R. Jungbauer, C. Weeks, and M. S. McDonagh, "Masks for prevention of respiratory virus infections, including SARS-CoV-2, in health care and community settings: a living rapid review," Ann. Intern. Med., vol. 173, no. 7, pp. 542-555, 2020, doi: 10.7326/M20-3213.

[18] T. Thi, P. Nguyen, L. H. Nguyen, H. T. Le, and G. T. Vu, "Perceptions and Attitudes Toward COVID-19-Related National Response Measures of Vietnamese: Implications for Pandemic Prevention and Control," Front. Public Heal., vol. 8, no. October, pp. 1-9, 2020, doi: 10.3389/fpubh.2020.589053.

[19] O. Ilesanmi and A. Afolabi, "Perception and practices during the COVID-19 pandemic in an urban community in Nigeria: a cross-sectional study," Peer J., vol. 8, p. e10038, 2020.

[20] R. E. Rad et al., "Application of the protection motivation theory for predicting COVID-19 preventive behaviors in Hormozgan, Iran: a cross-sectional study,” BMC Public Health, vol. 21, no. 1, pp. 1-11, 2021.

[21] M. Firouzbakht, S. Omidvar, S. Firouzbakht, and A. Asadi-Amoli, "COVID-19 preventive behaviors and influencing factors in the Iranian population; a web-based survey," BMC Public Health, vol. 21, no. 1, pp. 1-7, 2021, doi: 10.1186/s12889-021-10201-4.

[22] M. Vagni, T. Maiorano, V. Giostra, and D. Pajardi, "Coping with COVID-19: Emergency Stress, Secondary Trauma and Self-Efficacy in Healthcare and Emergency Workers in Italy," Front. Psychol., vol. 11, 2020.

[23] M. P. Matud, M. López-Curbelo, and D. Fortes, "Gender and psychological well-being," Int. J. Environ. Res. Public Health, vol. 16, no. 19, pp. 1-12, 2019, doi: 10.3389/fpsyg.2020.566912.

[24] B.-L. Zhong et al., "Knowledge, attitudes, and practices towards COVID-19 among Chinese residents during the rapid rise period of the COVID-19 outbreak: a quick online cross-sectional survey," Int. J. Biol. Sci., vol. 16, no. 10, pp. 1745-1752, 2020, doi: 10.7150/ijbs.45221.

[25] N. Shaukat, D. M. Ali, and J. Razzak, "Physical and mental health impacts of COVID-19 on healthcare workers: A scoping review," Int. J. Emerg. Med., vol. 13, no. 1, pp. 1-8, 2020, doi: 10.1186/s12245-020-00299-5. 
[26] A. Muhlisin and A. Pratiwi, "Community-based participatory research to improve primary mental health services," Int. J. Res. Med. Sci., vol. 5, no. 6, pp. 2524-2528, 2017, doi: 10.18203/2320-6012.ijrms20172441.

[27] D. Sharma, "COVID-19 (An International Trauma): A Brief Analysis on Research Trends, Impacts and Solutions," International Journal for Research in Applied Sciences and Biotechnology, vol. 7, no. 2, pp. 1-8, 2020, doi: 10.31033/ijrasb.7.2.1

[28] Y. Cheng, "Academic self-efficacy and assessment," International Journal of Experimental Educational Psychology, vol. 40, no. 4, pp. 389-391, 2020, doi: 10.1080/01443410.2020.1755501.

[29] L. Suwarni, D. Ismail, Y. S. Prabandari, and M. G. Adiyanti, "Perceived parental monitoring on adolescence premarital sexual behavior in Pontianak City, Indonesia," International Journal Public Health Science (IJPHS), vol. 4, no. 4, pp. 211-219, 2015, doi: 10.11591/ijphs.v4i3.4736.

[30] M. Barati et al., "Factors Associated with Preventive Behaviours of COVID-19 among Hospital Staff in Iran in 2020: An Application of the Protection Motivation Theory," J. Hosp. Infect., vol. 105, no. 3, pp. 430-433, 2020, doi: 10.1016/j.jhin.2020.04.035.

[31] I. Hossain, A. Mullick, A. Haidar, and M. M. Aktaruzzaman, "The COVID-19 Pandemic and Mental Health: A Systemic Review," Texila Int. J. Acad. Res., vol. 10, 2020.

[32] G. Roderique-Davies, C. McKnight, B. John, S. Faulkner, and D. Lancastle, "Models of health behaviour predict intention to use long-acting reversible contraception," Women's Heal., vol. 12, no. 6, pp. 507-512, 2016, doi: $10.1177 / 1745505716678231$.

\section{APPENDIX}

Table 3. Association between each independent variables and prevention behavior COVID-19

\begin{tabular}{|c|c|c|c|c|c|c|}
\hline \multirow{3}{*}{ Variables } & \multicolumn{4}{|c|}{ Prevention behavior of COVID-19 } & \multirow{3}{*}{ p-value } & \multirow{3}{*}{$\begin{array}{c}\text { OR } \\
(95 \% \mathrm{CI})\end{array}$} \\
\hline & \multicolumn{2}{|c|}{ Poor } & \multicolumn{2}{|c|}{ Good } & & \\
\hline & $\mathrm{n}$ & $\%$ & $\mathrm{n}$ & $\%$ & & \\
\hline \multicolumn{7}{|l|}{ Age } \\
\hline Youth & 99 & 41.6 & 50 & 34.0 & 0.138 & $1.38(0.90-2.12)$ \\
\hline Adult & 139 & 58.4 & 97 & 66.0 & & \\
\hline \multicolumn{7}{|l|}{ Gender } \\
\hline Male & 67 & 28.2 & 32 & 21.8 & 0.164 & $1.41(0.87-2.28)$ \\
\hline Female & 171 & 71.8 & 115 & 78.2 & & \\
\hline \multicolumn{7}{|l|}{ Occupation } \\
\hline Working/not working yet & 94 & 39.5 & 41 & 27.9 & $0.020 *$ & $1.69(1.08-2.63)$ \\
\hline Have a job & 144 & 60.5 & 106 & 72.1 & & \\
\hline \multicolumn{7}{|l|}{ Field of work } \\
\hline Non-health sector & 156 & 65.5 & 90 & 61.2 & 0.391 & $1.20(0.79-1.84)$ \\
\hline Health worker & 82 & 34.5 & 57 & 38.8 & & \\
\hline \multicolumn{7}{|l|}{ Degenerative disease history } \\
\hline No/Perhaps 'Yes' & 224 & 94.1 & 139 & 94.6 & 0.857 & $0.92(0.38-2.25)$ \\
\hline Yes & 14 & 5.9 & 8 & 5.40 & & \\
\hline \multicolumn{7}{|l|}{ COVID-19 cases all around } \\
\hline No/Perhaps 'Yes' & 211 & 88.7 & 123 & 83.7 & 0.161 & $1.52(0.84-2.76)$ \\
\hline Yes & 27 & 11.3 & 24 & 16.3 & & \\
\hline \multicolumn{7}{|l|}{ Perceptions of vulnerability } \\
\hline Low & 95 & 39.9 & 58 & 39.5 & 0.929 & $0.93(1.02-0.67)$ \\
\hline High & 143 & 60.1 & 89 & 60.5 & & \\
\hline \multicolumn{7}{|l|}{ Perception of severity } \\
\hline Low & 135 & 56.7 & 62 & 42.2 & $0.006^{*}$ & $1.80(1.19-2.72)$ \\
\hline High & 103 & 43.3 & 85 & 57.8 & & \\
\hline \multicolumn{7}{|l|}{ Perceptions of self-efficacy } \\
\hline Low & 135 & 56.7 & 32 & 21.8 & $<0.001^{*}$ & $4.71(2.95-7.52)$ \\
\hline High & 103 & 43.3 & 115 & 78.2 & & \\
\hline \multicolumn{7}{|l|}{ Efficacy response } \\
\hline Low & 125 & 52.5 & 41 & 27.9 & $<0.001^{*}$ & $2.86(1.84-4.45)$ \\
\hline High & 113 & 47.5 & 106 & 72.1 & & \\
\hline \multicolumn{7}{|l|}{ The evaluated cost response } \\
\hline Low & 145 & 60.9 & 51 & 34.7 & $<0.001 *$ & $2.93(1.91-4.50)$ \\
\hline High & 93 & 39.1 & 96 & 65.3 & & \\
\hline \multicolumn{7}{|l|}{ Protection intention } \\
\hline Low & 42 & 17.6 & 8 & 5.40 & $0.001 *$ & $3.72(1.69-8.17)$ \\
\hline High & 196 & 82.4 & 139 & 94.6 & & \\
\hline \multicolumn{7}{|l|}{ Protection motivation } \\
\hline Low & 34 & 14.3 & 9 & 6.10 & $0.013 *$ & $2.55(1.19-5.49)$ \\
\hline High & 204 & 85.7 & 138 & 93.9 & & \\
\hline \multicolumn{7}{|l|}{ Information circulating } \\
\hline Believe & 167 & 70.2 & 88 & 59.9 & $0.038 *$ & $1.57(1.02-2.43)$ \\
\hline Unbelieve & 71 & 29.8 & 59 & 40.1 & & \\
\hline \multicolumn{7}{|l|}{ Resource of information } \\
\hline Social media & 150 & 63.0 & 76 & 51.7 & $0.028 *$ & $1.59(1.05-2.42)$ \\
\hline Health worker & 88 & 37.0 & 71 & 48.3 & & \\
\hline
\end{tabular}

